\title{
Combination of cimetidine and alginic acid: an improvement in the treatment of oesophageal reflux disease
}

\author{
Cooperative Oesophageal Group
}

\begin{abstract}
A new chewable tablet containing cimetidine $200 \mathrm{mg}$ and alginic acid $500 \mathrm{mg}$, at a dosage of one tablet four times daily, was compared in a 12 week randomised study with the standard dosage of cimetidine ( $400 \mathrm{mg}$ four times daily) in the management of oesophageal reflux disease. The dose of cimetidine continued unchanged throughout the study but the dose of the combination drugs could be increased after six weeks to two tablets four times a day if response was unsatisfactory. A total of $\mathbf{3 1 2}$ patients had data suitable for analysis. Sixty three per cent of those on the combination tablet completed the study without increasing their dose - that is taking cimetidine equivalent to half the standard dosage used in the control group. The improvement in heartburn symptoms was significantly greater in the combination group than in the group taking full dose cimetidine. There were no significant differences between the treatment groups in healing and improvement of the appearances of oesophagitis after 12 weeks, and healing rates were as expected from previous studies. The addition of alginic acid to cimetidine in this fixed combination tablet is an improvement in symptomatic treatment of oesophageal reflux disease.
\end{abstract}

Oesophageal reflux disease is a common disorder, with up to $10 \%$ of the adult population experiencing heartburn daily. ${ }^{\prime}$ Reflux of gastric acid into the oesophagus is considered to be a major factor in producing symptoms and a significant cause of damage to the oesophageal mucosa. ${ }^{1}$ The aim of treatment is to control the symptoms of reflux, principally heartburn, and to heal oesophagitis.

Both the $\mathrm{H}_{2}$ receptor antagonists and preparations containing alginic acid are commonly used medical treatments for oesophageal reflux disease. These two treatments should be pharmacologically complementary, as $\mathrm{H}_{2}$ receptor antagonists reduce gastric acid secretion while alginic acid produces a viscous foam barrier to reflux of stomach contents into the oesophagus, and may also provide a protective lining for the oesophagus when reflux occurs. ${ }^{2}$ These treatments work by reducing the 'acid load' on the lower oesophagus by different mechanisms, and are often prescribed together, although pub- lished evidence of the efficacy of this combination is limited.

Two clinical pharmacology studies ${ }^{34}$ have suggested that concomitant use of cimetidine and alginic acid produces an additive beneficial effect on oesophageal $\mathrm{pH}$. The present study was designed to determine whether there is a clinical additive effect.

A new chewable tablet containing cimetidine $200 \mathrm{mg}$ and alginic acid $500 \mathrm{mg}$ (Algitec, Smith Kline and French Laboratories Ltd) was compared with the recommended dose of cimetidine in oesophageal reflux disease, which is $400 \mathrm{mg}$ four times daily. Although the bioavailability of cimetidine can vary according to the amount of alginic acid coadministered, it has been shown to be satisfactory in this preparation (unpublished data).

\section{Patients and methods}

The study was conducted in accordance with the Declaration of Helsinki (Venice 1983) and with local ethical committees' approval.

Hospital outpatients over the age of 18 years who had symptoms of gastro-oesophageal reflux disease and had given informed consent were recruited to the study. Those who were pregnant, had other upper abdominal complaints such as gall stones, or other significant disease were excluded, as were those who had received $\mathrm{H}_{2}$ receptor antagonists within the previous month.

After an initial assessment and no more than seven days before entry into the study, patients underwent endoscopy. The appearance of the oesophageal mucosa was graded ${ }^{5}$ grade $0=$ normal mucosa; grade $1=$ friability/erythema: grade 2 =discrete lesions - that is, erosions or multiple superficial ulcers; grade $3=$ confluent and longitudinal lesions, grade 4: circinate ulceration with or without complications - for example stenosis, Barrett's syndrome).

Patients with grade 4 oesophagitis were excluded. On this basis the patients were stratified into the two groups, those with oesophagitis of grade 1, 2, or 3 (group A) and those with normal mucosa (group B), before being randomly allocated to treatment with either cimetidine ( $400 \mathrm{mg}$ four times daily, with meals and at bedtime) or the cimetidine/alginic acid combination ( 1 tablet: (cimetidine $200 \mathrm{mg}$, 
alginic acid $500 \mathrm{mg}$ ) four times daily, after meals and at bedtime).

Patients returned for clinical assessment after three, six, nine, and 12 weeks of treatment. Those who had oesophagitis at entry underwent further endoscopy at week six and, if unhealed, at week 12. At week six the dose of the cimetidine/alginic acid combination could be increased from one to two tablets - that is cimetidine $400 \mathrm{mg}$, alginic acid $1 \mathrm{~g}$ ) - four times daily, if the investigator considered that the response had been unsatisfactory on endoscopic or symptomatic grounds, or both. Antacid tablets (Rennies: calcium carbonate, $680 \mathrm{mg}$ and light magnesium carbonate, $890 \mathrm{mg}$ ) were provided to be taken for relief of symptoms not controlled by the trial medication. No other medical treatment for reflux oesophagitis was allowed.

At initial assessment the medical history with details of gastrointestinal symptoms, particularly the frequency and severity of heartburn over the previous seven days, was obtained and patients made a global assessment of their wellbeing ( 1 =excellent, $2=$ good, $3=$ fair, $4=$ bad, $5=$ very bad).

Patients kept a daily diary during the study to record symptoms and antacid consumption. They were asked to note the number and severity of episodes of heartburn, whether or not they experienced epigastric pain, acid regurgitation, or odynophagia/dysphagia, and whether or not symptoms disturbed their sleep.

Assessment of these symptoms, overall wellbeing, compliance with the study medication (by tablet count), and details of concomitant medication including antacid use, were made after three, six, nine, and 12 weeks of treatment. Adverse events were monitored by physical examination and asking the patient, 'How have you been feeling?'

Two tailed tests were performed on the data to test whether or not there was a significant difference between the treatment groups, and the $95 \%$ confidence intervals for the difference were calculated. Statistical significance was assessed at the $5 \%$ level.

$\chi^{2}$ tests ${ }^{5}$ were used to compare the number of patients healed and the number of patients with an improvement in the appearances of oesophagitis on endoscopy at weeks six and 12 .

A $\log$ linear analysis ${ }^{6}$ was performed on the symptom data to see whether or not it was valid to combine the stratification groups $A$ and $B$ (presence and absence of signs of oesophagitis on endoscopy respectively). Where the groups could not be combined they were analysed separately.

Symptomatic data were compared between treatments at weeks six and 12 and, in addition, heartburn assessments were also compared at weeks three and nine.

$\chi^{2}$ tests were used to compare the treatments for incidence of heartburn and other gastrointestinal symptoms, sleep disturbance, improvement in heartburn and heartburn severity score, global assessment and improvement in global assessment scores, and consumption of antacids. Improvement was assessed by comparison with baseline values.

The median number of days of heartburn, number of episodes of heartburn, and antacid consumption per week were compared between treatments by non-parametric methods, using SAS procedure MRANK. ${ }^{?}$

\section{Results}

Thirty five centres in the UK, Republic of Ireland, and Holland entered 424 patients into the study. Data from 29 patients were excluded from analysis because they did not meet the protocol requirements for entry. In addition, a further 83 patients had inadequate data for analysis (40 on cimetidine and 43 on cimetidine/ alginic acid). Twenty three patients defaulted early, 31 withdrew because of adverse events or intercurrent illness and 29 were excluded from analysis because of non-compliance, failure to observe other protocol requirements, or a combination of these.

Of the 312 patients with data suitable for analysis, 158 were treated with cimetidine and 154 with cimetidine/alginic acid. The groups were balanced for age, sex, weight, duration of disease, and duration of present symptoms (Table I). The sex ratio was reversed for the treatment groups, women predominating in the cimetidine group and men in the cimetidine/ alginic acid group, but these differences were not statistically significant. Two hundred and seven patients had signs of oesophagitis on initial endoscopy (group A) and 105 had a normal mucosa (group B). Table II shows the number of patients in each endoscopic grade of oesophagitis.

Heartburn was the predominant symptom. In the week before the start of the study $93.0 \%$ ( 147 of 158) of patients subsequently treated with cimetidine and $89.6 \%$ (138 of 154$)$ who received cimetidine/alginic acid suffered from heartburn.

At week six the dosage of cimetidine/alginic acid was increased from one to two tablets four times daily in $34.4 \%$ (53 of 154) of the evaluable patients who entered the study. At week 12, $37 \cdot 3 \%$ ( 41 of 110 ) of patients remaining in the study were receiving the higher dose.

The cumulative healing rates for those with endoscopic oesophagitis were $65 \cdot 0 \%$ (52 of 80 )

TABLE I Treatment groups

\begin{tabular}{lll}
\hline & Cimetidine & $\begin{array}{l}\text { Cimetidinel } \\
\text { alginic acid }\end{array}$ \\
\hline Age: median (range) (yrs) & $50 \cdot 6(18 \cdot 8-83 \cdot 7)$ & $44 \cdot 8(19 \cdot 9-80 \cdot 2)$ \\
Sex: male & $77(48 \cdot 7 \%)$ & $86(55 \cdot 8 \%)$ \\
$\quad$ female & $80(50 \cdot 6 \%)$ & $68(44 \cdot 2 \%)$ \\
Weight: mean (kg) & $70 \cdot 5$ & $72 \cdot 8$ \\
Duration of disease: & $18 \cdot 0$ & $24 \cdot 0$ \\
$\quad$ median (mth) & & $12 \cdot 0$ \\
$\begin{array}{l}\text { Duration present symptoms: } \\
\text { median (wks) }\end{array}$ & $12 \cdot 0$ & \\
\hline
\end{tabular}

TABLE II Grading and appearance of the oesophageal mucosa at initial endoscopy

\begin{tabular}{lcc}
\hline Grade & $\begin{array}{l}\text { Cimetidine } \\
(\text { No }(\%))\end{array}$ & $\begin{array}{l}\text { Cimetidinel } \\
\text { alginic acid } \\
(\text { No }(\%))\end{array}$ \\
\hline 0 & $52(32 \cdot 9)$ & $53(34 \cdot 4)$ \\
1 & $23(14 \cdot 6)$ & $36(23 \cdot 4)$ \\
2 & $50(31 \cdot 6)$ & $37(24 \cdot 0)$ \\
3 & $33(20 \cdot 9)$ & $28(18 \cdot 2)$ \\
Total & 158 & 154 \\
\hline
\end{tabular}


TABLE III Median number of days of heartburn per week for patients still experiencing symptoms

\begin{tabular}{|c|c|c|c|c|c|c|}
\hline \multirow[b]{2}{*}{ Week } & \multicolumn{2}{|c|}{ Cimetidine } & \multicolumn{2}{|c|}{$\begin{array}{l}\text { Cimetidinel } \\
\text { alginic acid }\end{array}$} & \multirow[b]{2}{*}{$p$} & \multirow{2}{*}{$\begin{array}{l}95 \% \text { CI for } \\
\text { difference }\end{array}$} \\
\hline & Median & No & Median & No & & \\
\hline $\begin{array}{r}0 \\
6 \\
12\end{array}$ & $\begin{array}{l}7.0 \\
3 \cdot 5 \\
3.5\end{array}$ & $\begin{array}{r}147 \\
84 \\
58\end{array}$ & $\begin{array}{l}7 \cdot 0 \\
3 \cdot 0 \\
2 \cdot 3\end{array}$ & $\begin{array}{r}138 \\
78 \\
43\end{array}$ & $\begin{array}{l}\text { NS } \\
\text { NS } \\
\mathrm{p}<0.05\end{array}$ & $\begin{array}{r}0.0,1.0 \\
-0.4,0.8 \\
0.0,1.9\end{array}$ \\
\hline
\end{tabular}

for the cimetidine group and $66 \cdot 2 \%$ ( 49 of 74 ) for the cimetidine/alginic acid group at week 12, and the proportions showing improvement in the appearances of oesophagitis were $91 \cdot 3 \%$ (73 of 80 ) and $83.8 \%$ (62 of 74$)$ respectively.

There was a reduction in the percentage of patients experiencing any heartburn in both treatment groups over the study period (from $93.6 \%$ to $55 \cdot 2 \%$ for the cimetidine group and from $89.6 \%$ to $45 \cdot 3 \%$ for the cimetidine/alginic acid group). A statistically significant advantage was shown for the cimetidine/alginic acid group at week 12 for both the median number of days of heartburn per week for patients experiencing symptoms (Table III) and the improvement in heartburn (based on the change in number of days heartburn was reported) in those patients with heartburn at week 0 (Table IV).

For the other gastrointestinal symptoms and sleep disturbance no statistically significant differences were seen between the treatment groups, but the percentage of patients with an improvement in global assessment score showed a trend towards a greater improvement in the cimetidine/ alginic acid group at weeks six and 12; the $95 \%$ confidence intervals for the difference being $-18 \cdot 5 \%, 5 \cdot 1 \%$ and $-24 \cdot 1 \%, 1 \cdot 4 \%$ respectively. Significantly more patients with endoscopic oesophagitis treated with cimetidine were taking antacids at week 12 than patients treated with cimetidine/alginic acid $(67 \cdot 1 \%$ of the cimetidine group and $40.3 \%$ of the cimetidine/alginic acid group, $\mathrm{p}<0.01)$. There was no difference between treatments for those with normal mucosa on endoscopy.

Sixty seven parameters we tested statistically. The main proportion of these (38) being in the various testing of patient heartburn, days of heartburn, episodes of heartburn, severity of heartburn, and change in heartburn over time. The other parameters tested were endoscopic healing, improvement and grade, epigastric pain, acid reflux, odynophagia/dysphagia, disturbed sleep, global assessment, and use of antacids.

Nine of the 67 tests were statistically significant - all nine being in favour of the combination treatment. By chance, three statistically significant results could have been expected in 67 tests if the two products were not different in treatment effect. The probability of nine significant results all favouring the combination and occurring by chance is $\mathrm{p}<0 \cdot 002$.

TABLE IV Percentage of patients with an improvement in heartburn symptoms, compared with baseline

\begin{tabular}{llllc}
\hline Week & Cimetidine & $\begin{array}{l}\text { Cimetidinel } \\
\text { alginic acid }\end{array}$ & $p$ & $\begin{array}{l}95 \% \text { CI for } \\
\text { difference }\end{array}$ \\
\hline 6 & $78 \cdot 8 \%(104 / 132)$ & $77 \cdot 0 \%(87 / 113)$ & NS & $-8 \cdot 6 \%, 12 \cdot 2 \%$ \\
12 & $75 \cdot 3 \%(73 / 97)$ & $91 \cdot 6 \%(76 / 83)$ & $\mathrm{p}<0.01$ & $-26.8 \%,-5 \cdot 8 \%$ \\
\hline
\end{tabular}

To establish further the importance of the results, we examined all tested outcomes for favourable treatment effect and found that 45 results favoured the combination, 21 favoured cimetidine, and one was tied. The probability of this result is very significant $\mathbf{p}<0 \cdot 01$.

Adverse events were collected systematically throughout the study and were unremarkable. Thirty four patients were withdrawn from the study because of adverse events or intercurrent illness (cimetidine 19, cimetidine/alginate 15) and six withdrew because they did not like the taste of the cimetidine/alginic acid tablets.

\section{Discussion}

Several different medical treatments for symptomatic oesophageal reflux are available, besides the usual advice about weight loss, stopping smoking, and postural measures. These include antacids, alginic acid preparations, $\mathrm{H}_{2}$ receptor antagonists, and prokinetic agents. In view of the multiple aetiological factors involved, it is not surprising that no single medical treatment has proved entirely satisfactory. $\mathrm{H}_{2}$ receptor antagonists, for instance, are known to heal oesophagitis in about $60 \%$ of patients, rather less than the $80 \%$ success rate in healing peptic ulcer. ${ }^{8}$

The combination of treatments with complementary modes of action is therefore a logical step. The combination of an $\mathrm{H}_{2}$ receptor antagonist, cimetidine, and a prokinetic agent, metoclopramide, has been subjected to clinical trial ${ }^{9}$ but produced little, if any, improvement over cimetidine alone and was associated with an increased incidence of adverse reactions.

The combination of an $\mathrm{H}_{2}$ receptor antagonist with an alginic acid preparation is also logical and should produce no safety problems. The pharmacological rationale for this combination of treatments has been confirmed ${ }^{3}$ (Cushieri: personal communication) but little published information on clinical efficacy is available.

This study was designed to compare the efficacy of a new chewable tablet combining cimetidine $200 \mathrm{mg}$ and alginic acid $500 \mathrm{mg}$, given four times daily with the recommended dose of cimetidine in oesophageal reflux disease, $400 \mathrm{mg}$ four times daily. It showed that although two thirds of the patients receiving the combination tablet required only half the recommended daily dose of cimetidine, there was equivalent healing and improvement of endoscopic signs of oesophagitis and a superior control of the principle symptom heartburn. It would therefore seem that this combination tablet would be suitable for use in patients who have failed to respond to a simple alginate/antacid and in whom an $\mathrm{H}_{2}$ receptor antagonist would be considered appropriate treatment.

Investigators who participated in this study were as follows Great Britain: Dr G Birnie, Glasgow; Dr M Bramble, Middlesbrough; Dr W $R$ Burnham, Dr A McIntyre, Romford, Dr R Cockel, Birmingham; Mr M Cooper, Exeter; Dr J Dawson, Dr R Cockel, Birmingham; Mr M Cooper, Exeter; Dr J Dawson, Bebington; Dr M Denyer, Leeds; Dr T A Gson, Stafford; Dr M H Gleeson, Jersey; Mr N Hira, Oldham; Dr W S Hislop, Paisley; Dr R Long, Dr J F Mayberry, Nottingham; Dr B Linaker, Warrington; Dr R Machell, Truro; Dr V Mani, Leigh; Dr D Maxwell, London; Dr A S Mee, Reading, Dr P Miller, Manchester; Dr K Palmer, Edinburgh; Mr K Panesar, Londonderry; Dr R Russell, Glasgow; Mr G Sagor, St Albans; Dr T Sinclair, Aberdeen; Dr C Smith, Southampton; Dr P M Smith, Cardiff; Dr E T Swarbrick, 
Wolverhampton; Mr J G Temple, Birmingham; Dr A C Wicks, Leicester.

Republic of Ireland: Dr J Crowe, Dr E Clark, Dublin; Dr P W N Keeling, Dr N Kennedy, Dublin.

Holland: Dr C P M Dekkers, Breda; Dr H Mulder, Rotterdam Dr J A J Staal, Hengelo; Dr H A R E Tuynman, Roosendaal.

The group thanks Cynthia Haliburn and Elizabeth Else of Smith Kline and French who undertook the statistical analysis, and Smith Kline and French Laboratories Limited for their support of the study.

1 Wesdorp ICE. Reflux oesophagitis: a review. Postgrad Med $\mathcal{F}$ 1986; 62 (suppl 2): 43-5.

2 Beckloff GL, Chapman JH, Shiverdecker P. Objective evaluation of an antacid with unusual properties. $\mathcal{F}$ Clin Pharmacol tion of an antacid wi

3 Bennett JR, Buckton GK, Martin HD, Smith MR. The effect of adding cimetidine to alginate - antacid in treating gastrooesophageal reflux. In: Siewert JR, Hoelscher AH, eds.
Diseases of the esophagus. Berlin: Springer Verlag, 1988: 1111-5.

4 Eriksen CA, Cheadle WG, Cranford CA, Cushieri A. Combined cimetidine-alginate antacid therapy versus single agent treatment for reflux oesophagitis. Ann Chir Gynaecol, 1988; 77 133-7

5 Savary $\dot{M}$, Miller G. Oesophagus - endoscopy manual and atlas. Soleure: Gassmann AG, 1977.

6 Bishop YMM, Fienberg S, Holland P. Discrete multivariat analysis theory and practice. Boston: Massachusetts Institute of Technology Press, 1978.

7 SAS. SAS users group international, supplemental library user's guide. Cary NC: SAS Institute Inc, 1983.

8 Tytgat GNJ. Medical therapy of reflux esophagitis. In: Siewart JR, Hoelscher AH, eds. Diseases of the esophagus. Berlin: JR, Hoelscher AH, eds. Diseases
Springer Verlag, 1988: 1137-47.

9 Temple JG, Bradby GVH, O'Connor F, Panesar KS, Mulligan TO, Robinson TJ, Ward DW. Cimetidine and metoclopramide in oesophageal reflux disease. $B M \mathcal{F}$ 1983; 286: pramide
$1863-4$. 